\title{
Dynamic Characteristics of Rotor System with a Slant Crack Based on Fractional Damping
}

\author{
Zhinong $\mathrm{Li}^{1,2^{*}}$, Yunlong $\mathrm{Li}^{1}$, Dong Wang ${ }^{3}$, Zhike Peng ${ }^{3}$ and Haifeng Wang ${ }^{1}$
}

\begin{abstract}
The traditional modeling method of rotor system with a slant crack considers only integer-order calculus. However, the model of rotor system based on integer-order calculus can merely describe local characteristics, not historical dependent process. The occur of fractional order calculus just makes up for the deficiency in integer-order calculus. Therefore, a new dynamic model with a slant crack based on fractional damping is proposed. Here, the stiffness of rotor system with a slant crack is solved by zero stress intensity factor method. The proposed model is simulated by Runge-Kutta method and continued fraction Euler method. The influence of the fractional order, rotating speed, and crack depth on the dynamic characteristics of rotor system is discussed. The simulation results show that the amplitude of torsional excitation frequency increases significantly with the increase of the fractional order. With the increase of the rotating speed, the amplitude of first harmonic component becomes gradually larger, the amplitude of the second harmonic becomes smaller, while the amplitude of the other frequency components is almost invariant. The shaft orbit changes gradually from an internal 8-type shape to an ellipse-type shape without overlapping. With the increase of the slant crack depth, the amplitude of the transverse response frequency in the rotor system with a slant crack increases, and the amplitude in the second harmonic component also increases significantly. In addition, the torsional excitation frequency and other coupling frequency components also occur. The proposed model is further verified by the experiment. The valuable conclusion can provide an important guideline for the fault diagnosis of rotor system with a slant crack.
\end{abstract}

Keywords: Fractional calculus, Slant crack, Rotor system, Dynamic characteristics

\section{Introduction}

Since the long-term transverse bending fatigue, the shaft is easy to form traversing cracks during the service period or beyond the service period. At present, the dynamic characteristics of rotor system with traversing cracks have been widely studied [1-8]. However, in engineering practice, many rotating shafts can also be used to transfer torque, which will inevitably produce slant cracks. In the 1880 s, Ichimonji et al. [9] proposed the model of rotor system with a slant crack under the transversal steady state. He thought the response frequency of rotor system consists of

\footnotetext{
${ }^{*}$ Correspondence: lizhinong@tsinghua.org.cn

${ }^{1}$ Key Laboratory of Nondestructive Testing, Ministry of Education,

Nanchang Hangkong University, Nanchang 330063, China

Full list of author information is available at the end of the article
}

frequency multiplication components and coupled frequency caused by the torsional excitation. Later, Sekhar et al. [10] used the similar solution method of transverse crack stiffness to solve the stiffness of the rotating shaft with a slant crack, and obtained the response frequency of rotor system in the transverse vibration base on the dynamic equations constructed by the finite element method. Darpe [11, 12] proposed the threedegree-of-freedom and four-degree-of-freedom equations of rotor system with a slant crack respectively. Based on these proposed equations, the influence of the slant crack angle on the stiffness of rotor system was studied. Considering the response frequency of rotor system in the transverse vibration, he also compared the torsional excitation frequency of transverse crack with that of the slant crack. Based on the relationship between the stress intensity factor (SIF) and the strain
Springer Open

(c) The Author(s) 2021. This article is licensed under a Creative Commons Attribution 4.0 International License, which permits use, sharing, adaptation, distribution and reproduction in any medium or format, as long as you give appropriate credit to the original author(s) and the source, provide a link to the Creative Commons licence, and indicate if changes were made. The images or other third party material in this article are included in the article's Creative Commons licence, unless indicated otherwise in a credit line to the material. If material is not included in the article's Creative Commons licence and your intended use is not permitted by statutory regulation or exceeds the permitted use, you will need to obtain permission directly from the copyright holder. To view a copy of this licence, visit http://creativeco mmons.org/licenses/by/4.0/. 
energy release rate (SERR) in fracture mechanics, Lin et al. [13] derived the coupled stiffness of rotor system with an open-type crack of 45-degree, and further used the Runge-Kutta method to solve the dynamic equations with coupled stiffness, and analyzed the influence of the crack depth, eccentricity, and rotating speed on the dynamic characteristics of rotor system with a slant crack. On the basis of material mechanics and fracture mechanics, Li et al. [14, 15] used the strain energy release rate (SERR) to obtain the stiffness matrix of rotor system with a slant crack, and discussed the influence of crack angle, slender ratio of shaft and crack depth on the stiffness of rotor system with a fully open crack. In addition, Refs. [14, 15] also analyzed the variation of nonlinear output frequency response function value in rotor system. Yu [16] proposed a finite element model of the Timoshenko beam, used the crack closure line method to describe the breath effect of crack, and compared the stiffness of rotor system with different crack angles. The results showed that the stiffness of rotor system changed nonlinearly with the angle of slant crack. Jiao et al. [17] deduced the flexibility matrix and stiffness matrix of arbitrary spatial slantcrack and analyzed the variable stiffness characteristics of traversing crack, transverse-slant-crack, and spatial slant-crack. The results showed the shear stiffness of spatial slant-crack in the axial and vertical direction was very obvious. Lu et al. [18] used the energy principle to derive the stiffness matrix of an element with a slant crack, and used the crack closure line method to simulate the breathing behaviour of slant crack, and used the finite element method to construct the coupled dynamic equations of rotor system with a breathing crack base on the static unbalance and eccentricity distance.

The above proposed models of rotor system with a slant crack are based on integer-order calculus. However, in these dynamic models of rotor systems with a slant crack, the influence of fractional order characteristics of damping in rotor system is ignored. Therefore, it is necessary to introduce fractional damping into modeling of rotor system with slant crack. Compared with integerorder calculus, fractional-order calculus has the following advantages.

(1) Fractional calculus has global correlation and can better reflect the history-dependent process of system function development. However integer-order calculus has locality and is not suitable for describing history-dependent process.

(2) The fractional calculus model overcomes the serious shortcoming, i.e. the theory does not agree well with the experimental results in the classical integer-order differential model, and can use fewer parameters to obtain good results.

(3) Compared with the traditional nonlinear model, the physical meaning of the fractional model is clearer and the expression is more concise when the fractional calculus model is used to describe complex physical and mechanical problems.

In recent years, the fractional calculus has been successfully applied to the nonlinear dynamic analysis of rotor system [19-21]. For example, Xue et al. [22, 23] used fractional damping to proposed a transverse crack model of Jeffcott rotor system. However, the proposed equations only considered the transverse crack, not considered a slant crack. Here, fractional order calculus is introduced into the modeling of rotor system with a slant crack. The fractional damping model of rotor system with a slant crack is proposed, and the dynamic characteristics of the proposed model are studied.

The structure of this paper is as follows. In Section II, the first stress intensity factor (FSIF) of rotor system is calculated. In Section III, the flexibility of rotor system with a slant crack is calculated, and the variation of the additional flexibility of rotor system with a slant crack from opening to closing is studied. In Section IV, a dynamic model of rotor system with a slant crack based on fractional damping is proposed and solved by the four-order Runge-Kutta method. According to the axis orbit and double-frequency diagram, the influence of fractional order, rotating speed, and crack depth on the dynamic characteristics is discussed. In Section V, the experiments are completed on a rotor test rig in order to analyze the dynamic characteristics of rotor system with a slant crack at different rotational speeds. In Section VI, some valuable conclusions of this paper are given.

\section{Basic Principle of SIF $=0$}

In the theory of fracture mechanics, the first stress intensity factor $K_{I}$, the second stress intensity factor $K_{I I}$, and the third stress intensity factor $K_{I I I}$ can be used to represent by the crack-tip of opening-type crack (i.e., type-I crack), shear-type crack (i.e., type-II crack) and tear-type crack (i.e., type-III crack) respectively [24]. The opening and closing degree of the crack is related to the stress distribution at the edge of the crack, that is, to the value of the first stress intensity factor $K_{I}$ at the edge of the crack. When $K_{I}>0$, the corresponding crack is in the open region, and when $K_{I}<0$, the corresponding crack is in the close region. Therefore, the line of the first stress intensity factor $K_{I}=0$ can be used to distinguish the open and closed regions of the crack.

The diagrammatic sketch of the parameters of cracksection is shown in Figure 1. In Figure 1, $\xi^{\prime} O^{\prime} \eta$ ' is the 


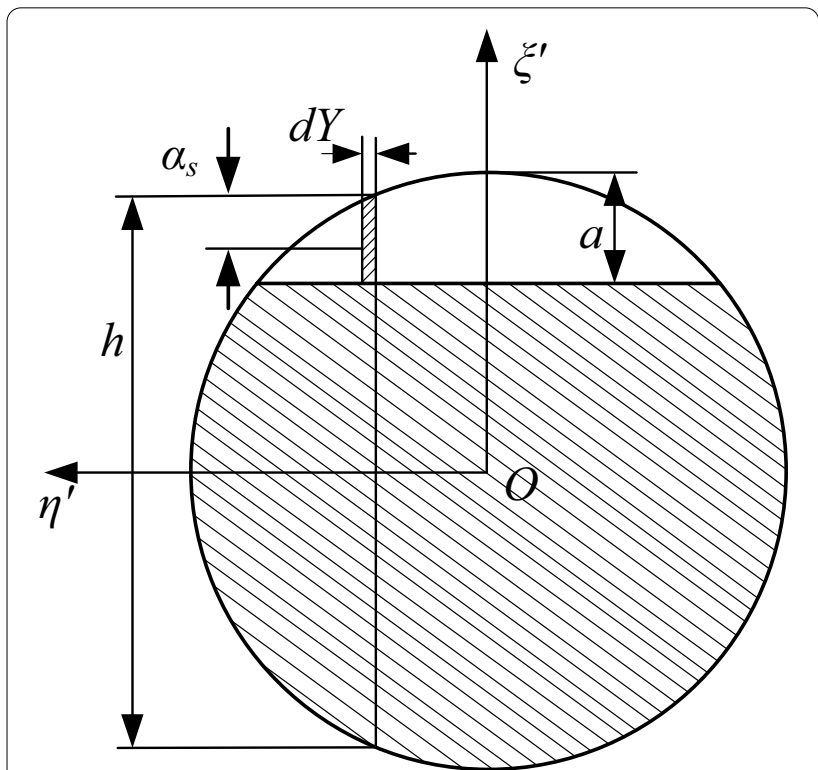

Figure 1 Diagrammatic sketch of the parameters of crack section

coordinate axis fixed at the shaft center, $a$ is the depth of the crack, $d \eta$ ' is the thickness of a sheet with a certain crack depth, $h$ is the width of the sheet, $\alpha_{s}$ is the specified depth of the sheet. At any position of the crack area on the crack surface, the total first stress intensity factor $K_{I}$ can be expressed as follows

$$
K=K_{\xi^{\prime}}+K_{\eta^{\prime}},
$$

where $K_{I \xi}$ and $K_{I \eta}$, are the first stress intensity factor FSIF on the $\xi^{\prime}$-axis and $\eta$ '-axis respectively [25] and can be calculated by Eqs. (2) and (3):

a Shaft with a slant crack of $45^{\circ}$

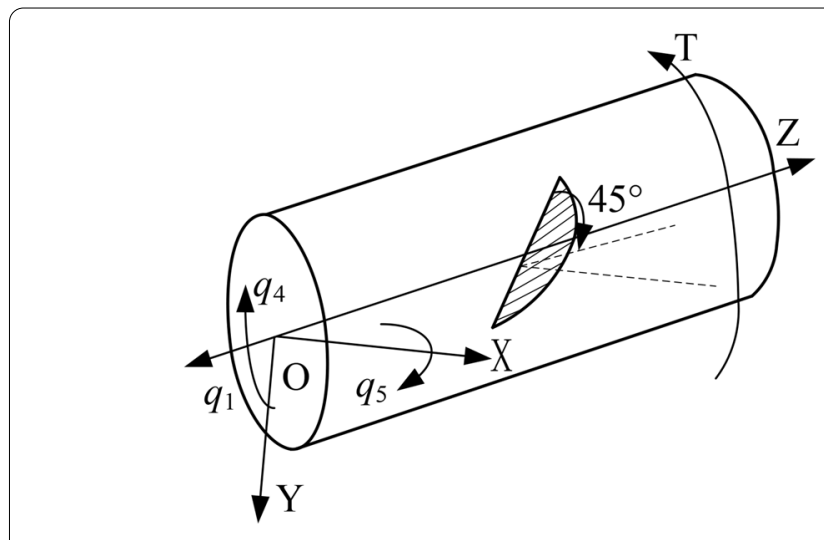

$$
\begin{aligned}
& K_{\xi^{\prime}}=\frac{Q_{\xi} l \sqrt{R_{2}-\eta_{2}}}{\pi R^{4}} F_{2}\left(\frac{\alpha_{s}}{h}\right) \sqrt{\pi \alpha_{s}}, \\
& K_{\eta^{\prime}}=\frac{Q_{\eta} l \eta}{\pi R^{4}} F_{1}\left(\frac{\alpha_{s}}{h}\right) \sqrt{\pi \alpha_{s}},
\end{aligned}
$$

where $F_{2}\left(\frac{\alpha_{s}}{h}\right)$ and $F_{1}\left(\frac{\alpha_{s}}{h}\right)$ are two influence coefficients, $Q_{\xi}$ and $Q_{\eta}$ are the sums of internal forces on the $\xi^{\prime}$-axis and $\theta^{\prime}$-axis respectively, $l$ is the length of the shaft, $R$ is the radius of the shaft, $\eta$ is the distance from the crack edge to the shaft center.

\section{Additional Flexibility of Rotor System with a Slant Crack}

Figure 2(a) is the diagrammatic sketch of rotor system with a slant crack of $45^{\circ}$, and Figure 2(b) is the diagrammatic sketch of crack section. In Figure 2, XOY is the coordinate axis fixed at the shaft center. The four loads subjected to the shaft are respectively the axial force $q_{1}$, the torque $T$, the bending moment $q_{4}$ and the bending moment $q_{5}$ in two directions.

In the Ref. [26], under different stresses, the stress intensity factor (SIF) of a unit thickness sheet with a certain crack depth was given. In order to obtain the stiffness of the cracked shaft, the shaft is divided into numerous thin sheets of thickness $d Y$ along the direction perpendicular to the $y$-axis to form the thin plates with one-side cracks of width $h=2 \sqrt{R^{2}-d Y^{2}}$, thickness $d Y$, and crack depth $a$. Based on the formula of stress intensity factor (SIF) and the relationship between SIF and the strain energy release rate (SERR) [27], the energy release rate of slat body with one-sided crack is obtained. The energy release rate is integrated on the whole crack cross section to obtain the strain energy release rate released by the whole crack body. Then, the additional flexibility

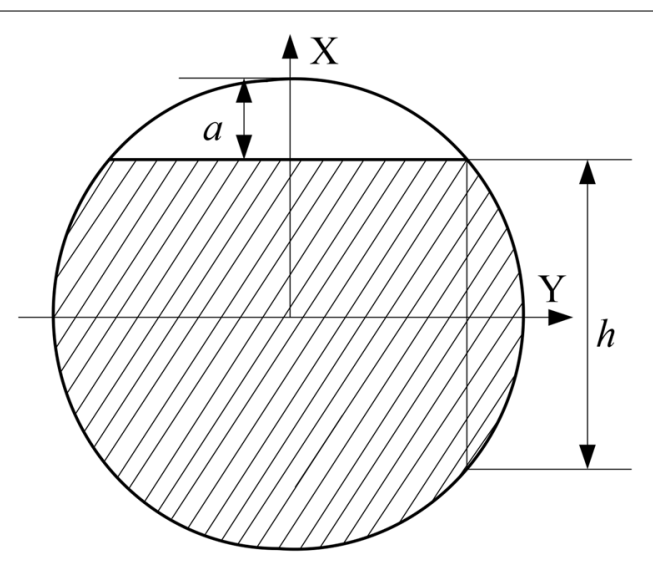

b Slant crack section

Figure 2 Diagrammatic sketch of the shaft with a slant crack and the slant crack section 
of rotor system is calculated by Castigliano's theorem. The flexibility of the cracked rotor is the sum of the additional flexibility and the flexibility of the shaft without crack. The stiffness of a patterned rotor is the inverse of the rotor compliance or the inverse of the rotor compliance matrix.

In order to obtain the additional flexibility of the cracked shaft, first, the stress intensity factor on the crack section should be calculated when the crack depth is $a$. For rotor system with a slant crack, the stress intensity factor generated by the four loads subjected to cracked shaft are respectively as follows:

$$
\begin{aligned}
& q_{1}: K_{I 1}=\sigma_{1} \sqrt{\pi a} F_{1} \quad \sigma_{1}=\frac{q_{1}}{2 \pi R^{2}}, \\
& K_{I I I 1}=\tau_{1} \sqrt{\pi a} F_{3} \quad \tau_{1}=\frac{q_{1}}{2 \pi R^{2}}, \\
& q_{4}: K_{I 4}=\sigma_{4} \sqrt{\pi a} F_{1} \quad \sigma_{4}=\frac{2 q_{4} d Y}{\pi R^{4}}, \\
& q_{5}: K_{I 5}=\sigma_{5} \sqrt{\pi a} F_{2} \quad \sigma_{5}=\frac{q_{5} h}{\pi R^{4}}, \\
& K_{I I I 5}=\tau_{5} \sqrt{\pi a} F_{3} \quad \tau_{5}=\frac{q_{5} h}{\pi R^{4}}, \\
& T: K_{I T}=\sigma \sqrt{\pi a} F_{2} \quad \sigma=\frac{2 T \sqrt{d Y^{2}+\left(\frac{h}{2}\right)^{2}}}{\pi R^{4}}
\end{aligned}
$$

where $\sigma_{1}, \sigma_{4}, \sigma_{5}$, and $\sigma$ are respectively the maximum tensile stresses generated by $q_{1}, q_{4}, q_{5}$, and $T, \tau_{1}$ and $\tau_{5}$ are respectively the shear stresses generated by $q_{1}$ and $q_{5}$. Therefore, the total stress intensity factor is

$$
\begin{aligned}
& F_{2}=\sqrt{\frac{\tan \lambda}{\lambda}}\left[0.923+0.199(1-\sin \lambda)^{4}\right] \frac{1}{\cos \lambda}, \\
& F_{3}=\sqrt{\frac{\tan \lambda}{\lambda}} .
\end{aligned}
$$

The density function of strain energy release rate (SERR) is expressed as follows [29]:

$$
J=\frac{1}{E^{\prime}}\left[K_{I}^{2}+(1+v) K_{I I I}^{2}\right],
$$

where $E^{\prime}$ is the elastic modulus of the shaft, $v$ is the crack opening displacement.

Suppose $A$ ' is the opening region of the crack (i.e., the first stress intensity factor $K_{I}>0$ ), strain energy release rate (SERR) of rotor system can be expressed as

$$
W=\iint_{A^{\prime}} \frac{K_{I}^{2}}{E^{\prime}} \mathrm{d} a \mathrm{~d} Y+\iint_{A^{\prime}} \frac{K_{I I I}^{2}(1+v)}{E^{\prime}} \mathrm{d} a \mathrm{~d} Y .
$$

According to Castigliano's theorem, the additional flexibility of rotor system can be obtained as follows:

$$
\left[\Delta c_{i j}\right]=\frac{\partial^{2} W}{\partial q_{i} \partial q_{j}} .
$$

Under the action of an unbalanced force, the axial force, and torque, the flexibility of the shaft without crack is

$$
\left[\Delta c_{s}\right]=\operatorname{diag}\left[\frac{l^{3}}{48 E I}, \frac{l^{3}}{48 E I}, \frac{l}{2 E A}, \frac{l}{2 E A}\right],
$$

where $I$ is the moment of inertia of the section, $A$ is the area of the section.

The flexibility of the cracked shaft is the sum of the

$$
\begin{aligned}
& K_{I}=K_{I 1}+K_{I 4}+K_{I 5}+K_{I T} \\
& =\left(\frac{q_{1}}{2 \pi R^{2}}+\frac{2 q_{4} b}{\pi R^{4}}\right) \sqrt{\pi a} F_{1}+\left[\frac{q_{5} h}{\pi R^{4}}+\frac{2 T{\sqrt{d Y^{2}+\left(\frac{h}{2}\right)}}^{2}}{\pi R^{4}}\right] \sqrt{\pi a} F_{2},
\end{aligned}
$$

$$
K_{I I I}=K_{I I I 1}+K_{I I I 5}=\left(\frac{q_{1}}{2 \pi R^{2}}+\frac{q_{5} h}{\pi R^{4}}\right) \sqrt{\pi a} F_{3} .
$$

Suppose $\lambda=\pi \alpha / 2 h$, according to Ref. [28], the three influence coefficients are respectively as follows:

$$
F_{1}=\sqrt{\frac{\tan \lambda}{\lambda}}\left[0.752+2.02\left(\frac{a}{h}\right)+0.37(1-\sin \lambda)^{3}\right] \frac{1}{\cos \lambda},
$$

additional flexibility and the flexibility of the shaft without crack [30], i.e.,

$$
[\Delta c]_{1}=\left[G_{1}\right][\Delta c]\left[G_{2}\right]+\left[c_{s}\right]
$$

where $\left[G_{1}\right]$ and $\left[G_{2}\right]$ are transformation matrices, which are mainly used to convert the rotation imbalance force, axial force, and torque to the two ends of the shaft in Figure 2. The transformation matrices are calculated as follows: 


$$
\begin{aligned}
& {\left[G_{1}\right]=\operatorname{diag}\left[\frac{l}{2}, \frac{l}{2}, 1,1\right],} \\
& {\left[G_{4}\right]=\operatorname{diag}\left[\frac{l}{4}, \frac{l}{4}, 1,1\right] .}
\end{aligned}
$$

When calculating the additional flexibility of the shaft with a slant crack, the parameters are set as follows. The length of the shaft is $L=260 \mathrm{~mm}$, the crack depth is $a$ $=d / 2$, and the diameter of the shaft is $d=9.5 \mathrm{~mm}$. The variation of the slant cracked shaft with the additional flexibility of the crack from closing to opening is shown in Figure 3. In Figure 3, the ordinate axis represents the additional flexibility (unit: $\mathrm{m} / \mathrm{N}$ ), and the horizontal axis represents the boundary line of the crack opening area to the boundary line of the entire crack area. $c(i, j)$ represents the additional displacement in the $j$ direction under the unit force acting in the $i$ direction, and 1, 2, 3, 4 represent two bending moment direction of the $x$-axis and $y$-axis, torque direction and axial direction respectively.

\section{Dynamic Characteristics of Rotor System with a Slant Crack Based on Fractional Damping}

In the rotor system, if the shaft is impacted by torsional vibration for a long time, it is easy to form a slant crack with an angle of about $45^{\circ}$ in the shaft. Here, considering the influence of the transverse, torsional and axial motion on rotor system, the dynamic equation of the rotor system with a slant crack based on fractional damping is proposed, and the dynamic characteristics of rotor system with a slant crack are discussed.

In the case of torsional vibration, the Jeffcott rotor model is shown in Figure 4. In Figure 4, $\Omega$ represents the rotating speed, $t$ represents time, $\Omega t+\alpha$ is the rotating angle of the disc, $\phi$ is the torsion angle in the torsion direction.

The proposed dynamic equations of the rotor system with a slant crack is solved by the Runge Kutta method and continued fraction Euler method, and the steadystate responses in all directions are obtained. Then the Fourier transform method is used to process the obtained vibration signals. Finally, the vibration spectrum of the rotor system with a slant crack is obtained.

The Lagrangian equation is used to establish the dynamic equations of rotor system with a slant crack based on fractional damping in the transverse, torsion, and axial direction respectively.

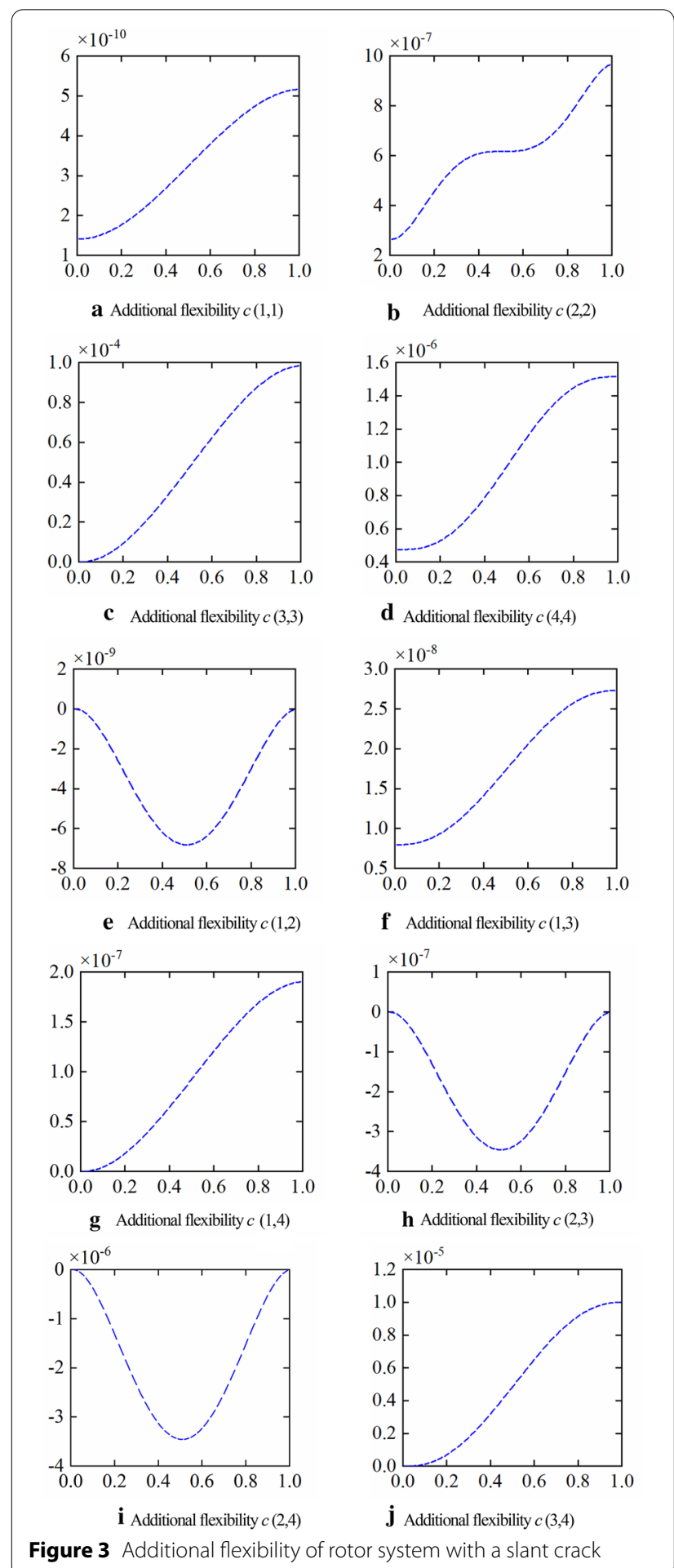

$$
\begin{aligned}
& m \ddot{x}+c D^{r} x+k_{x} x+k_{x y} y+k_{x T} \alpha+k_{x u} u= \\
& -m g+m e\left(\Omega+D^{r} \alpha\right)^{2} \cos (\Omega t+\alpha+\varphi)+m e \ddot{\alpha} \sin (\Omega t+\alpha+\varphi),
\end{aligned}
$$




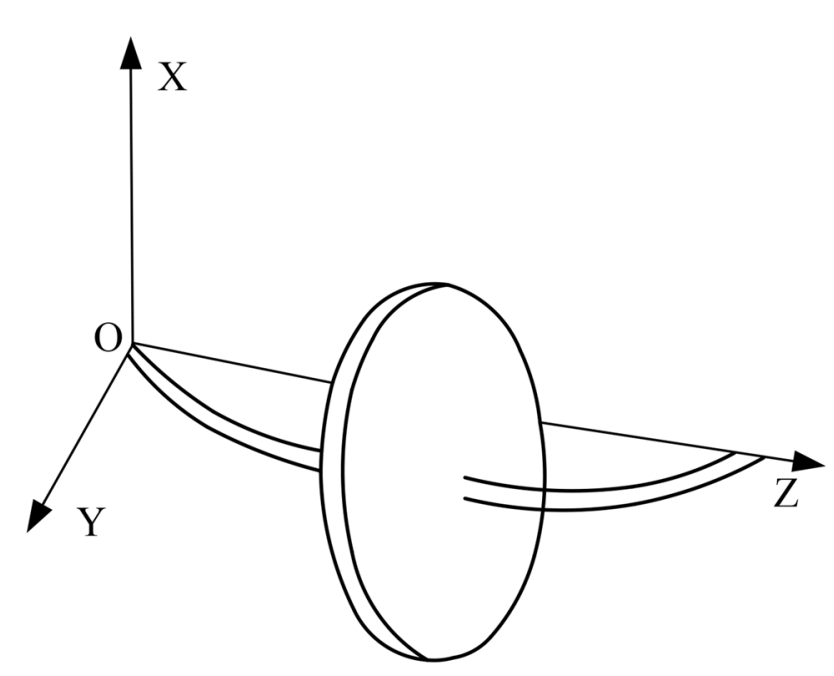

a Model of Jeffcott rotor system

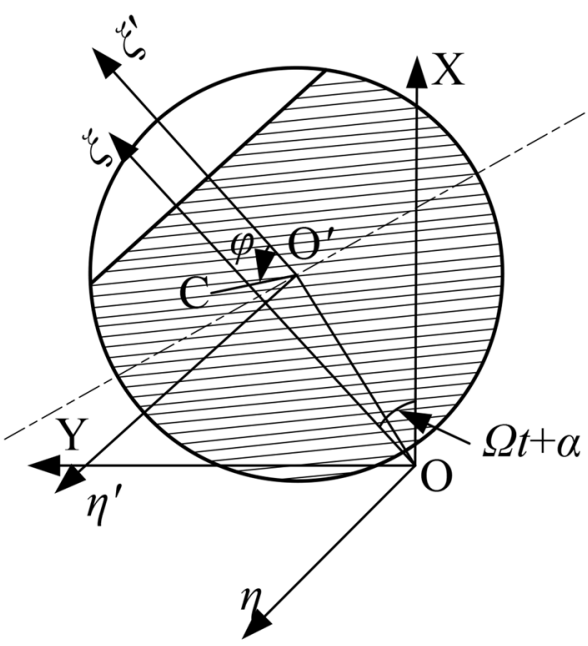

b Projection of crack-section along the $Z$-direction

Figure 4 The Jeffcott rotor system with a slant crack of $45^{\circ}$ and the projection of crack-section in the Z-direction

$$
\begin{aligned}
& m \ddot{y}+c D^{r} y+k_{x y} x+k_{y} y+k_{y T} \alpha+k_{y} u= \\
& m e\left(\Omega+D^{r} \alpha\right)^{2} \sin (\Omega t+\alpha+\varphi)-m e \ddot{\alpha} \cos (\Omega t+\alpha+\varphi),
\end{aligned}
$$

$$
\begin{aligned}
& J_{p} \ddot{\alpha}+c_{T}\left(\Omega+D^{r} \alpha\right)+k_{x T} x+k_{y T} y+k_{T u} u= \\
& M(t)+m g \sin (\Omega t+\alpha+\varphi)+m \ddot{x}(\Omega t+\alpha+\varphi)-m \ddot{y} e \cos (\Omega t+\alpha+\varphi),
\end{aligned}
$$

The parameters required to solve the above equations are as follows. $m=0.595 \mathrm{~kg}, L=260 \mathrm{~mm}, d=9.5 \mathrm{~mm}$, $E=210 \mathrm{GPa}, c=41.65 \mathrm{~kg} / \mathrm{s}, c_{T}=0.0091 \mathrm{~kg} \cdot \mathrm{m}^{2} / \mathrm{s}, c_{u}=$

$$
m \ddot{u}+c_{u} D^{r} u+k_{x u} x+k_{y u} y+k_{T u} \alpha+k_{u} u=0,
$$

where $m$ is the mass of the disc, $J_{p}$ is the moment of inertia of the disc, $c$ is the damping coefficient in the transverse direction, $c_{T}$ is the damping coefficient in the torsion direction. $c_{u}$ is the damping coefficient in the axial direction, $x$ and $y$ is the displacement, $D^{r}$ is the transformation coefficient of fractional order damping force, $u$ is the displacement in the axial direction, $e$ is the eccentric distance of the disc, $M(t)$ is the torsional excitation. The stiffness matrix in fixed coordinate system is as follows:

$$
[k]=\left|\begin{array}{cccc}
k_{x} & k_{x y} & k_{x T} & k_{x u} \\
k_{x y} & k_{y} & k_{y T} & k_{y u} \\
k_{x T} & k_{y T} & k_{T} & k_{T u} \\
k_{x u} & k_{y u} & k_{T u} & k_{u}
\end{array}\right|,
$$

where $k_{x}, k_{y}, k_{T}$, and $k_{u}$ are respectively the stiffness in the two transverse directions of $x$-axis and $y$-axis, torsional direction, and axial direction, $k_{x y}, k_{x T}, k_{y T}, k_{x w}, k_{y w}$ and $k_{T u}$ are the coupling stiffness. In the most practical rotor system, the excitation force in the axial direction is small or even rare. So, the axial excitation force is not considered in Eq. (25).
$146.2034 \mathrm{~kg} / \mathrm{s}$. The diameter of the disc is $d_{p}=76 \mathrm{~mm}$. The phase angle of the disc is $\phi=\pi / 6$. The frequency of the torsional excitation is $\omega_{T}=0.6 \Omega$. Poisson's ratio is $v=0.3$. The eccentricity of the disc is obtained by adding a screw with the weight of $d_{m}=3 \mathrm{~g}$ at a distance of $32.75 \mathrm{~mm}$ from the center of the disc.

\subsection{Influence of the Fractional Order on the Dynamic Characteristics of Rotor System with a Slant Crack}

In this section, the same crack depth and the same speed, we discuss the influence of the fractional order on the nonlinear dynamic characteristics of the rotor system with a slant crack based on fractional order damped. Here, crack depth is set to $a=d / 2$, the rotating speed is set to $\Omega=300 \mathrm{r} / \mathrm{min}$.

From Figure 5 and Figure 6, the fractional order has a great influence on the dynamic characteristics of rotor system with a slant crack. When the fractional order is $r=0.2$, the shaft orbit of the rotor system is a typical internal 8-type shape. In the transverse spectrum, there is only the first harmonic component caused by unbalanced and the second harmonic component caused 


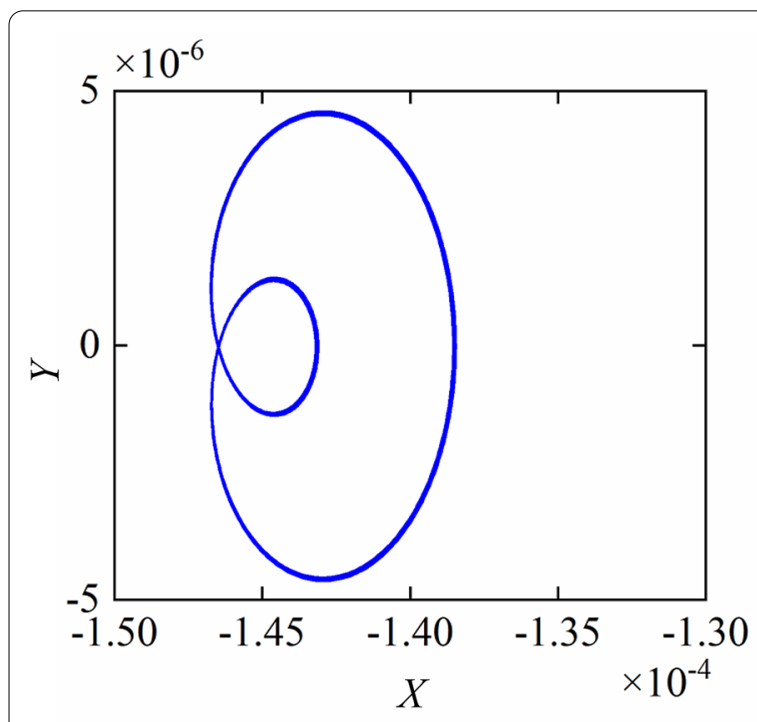

a $r=0.2$

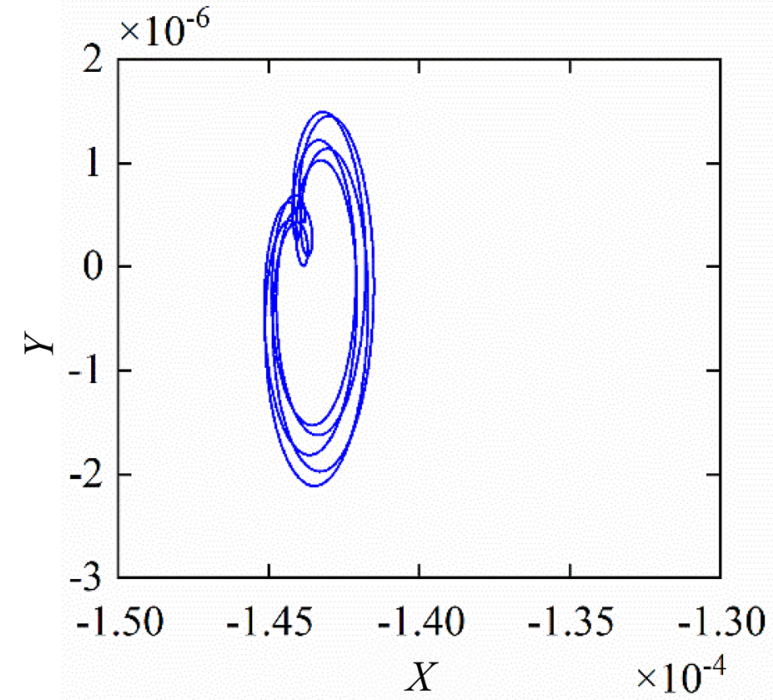

c $r=0.5$

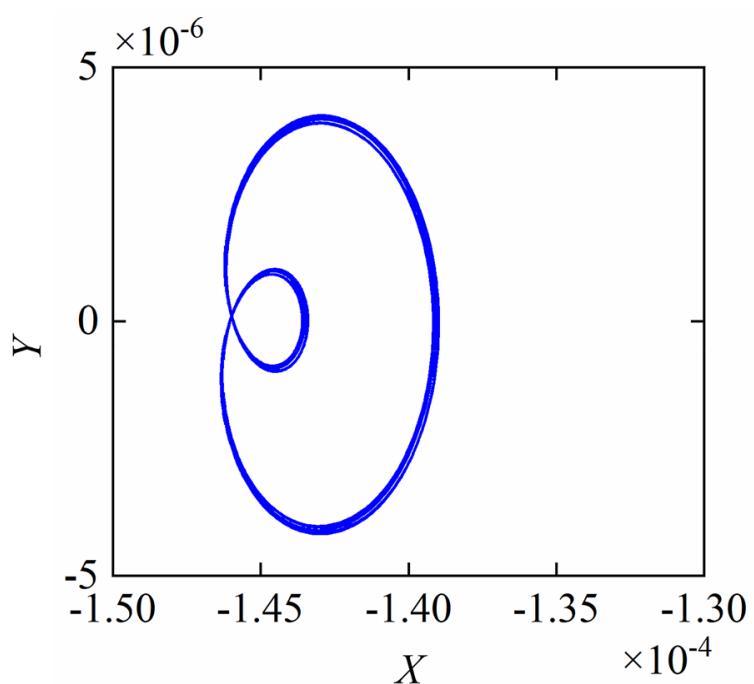

b $r=0.3$

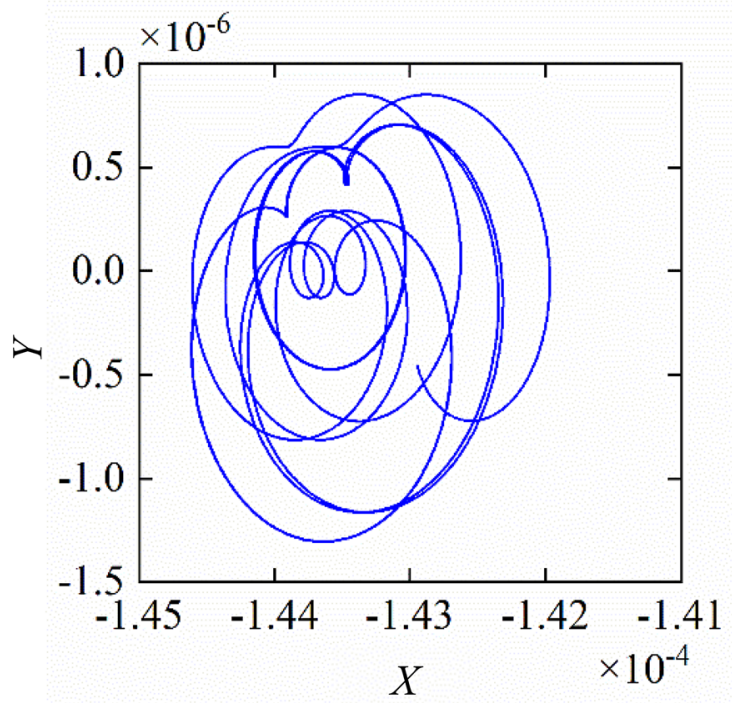

d $r=0.7$

Figure 5 Shaft orbit of rotor system with a slant crack based fractional damping (under the different fractional order)

by the crack. In the axial direction, there is the $1 / 2$ order harmonic component, which is relatively weak than the first harmonic component. Because the shaft with a slant crack is subjected to torsion, tension, and bending moments, the stiffness of the shaft will occur tension-bending coupling, bending-torsional coupling, and tension-torsional coupling, the coupling frequency components will occur in the transverse spectrum diagrams. The inner circle in the shaft orbit of the rotor system gradually becomes smaller as the fractional order gradually increases. In the transverse spectrum diagram, the coupling frequency components become more and more obvious and their amplitudes gradually become larger. However, the amplitude of the first 
harmonic component and second harmonic component becomes smaller. The amplitude of the spectrum in the axial direction also gradually decreases.

\subsection{Influence of Rotating Speed on the Dynamic Characteristics of Rotor System with a Slant Crack}

In this section, under the same crack depth and the same fractional order, we discuss the influence of rotating speed on the dynamic characteristics of rotor system with a slant crack based on fractional damping. Here, the crack depth is set to $a=d / 2$, the fractional order is set to $r=0.4$.

From Figure 7 and Figure 8, the rotating speed has a great influence on the dynamic characteristics of the rotor system with a slant crack. When the rotating speed close to the critical speed or the subcritical speed, the noninear dynamic characteristics of the rotor system with a slant crack are very obvious. In Figure 7, when the rotating speed is relatively low, the shaft orbit is a typical internal 8-type shape. In the transverse spectrum, the first harmonic and second harmonic are the main components. The amplitude of the second harmonic is greater than that of the first harmonic, the characteristic frequency of the crack is obvious. However, the other coupling frequency multiplication components are not prominent. In the axial spectrum, the 1/2-order harmonic component is the main component, however the first harmonic is weak. The shape of the shaft orbit in the rotor system with a slant crack gradually changes from an internal 8-type shape to an ellipse-type shape with the increase of the rotating speed. Because the shaft with a slant crack is subjected to the interference of the coupling stiffness, the ellipse-type shape in the shaft orbit is not overlapped together. In the transverse spectrum, the amplitude of the first harmonic gradually becomes larger. However, the amplitude of the second harmonic gradually becomes smaller or even disappears. In addition, the variation of the amplitude of the other coupling frequency multiplication components is almost obvious. In the axial spectrum diagram, the amplitudes of each frequency become gradually smaller.

\subsection{Influence of the Crack Depth on the Dynamic Characteristics of Rotor System with a Slant Crack}

In this section, under the same fractional order and the same rotating speed, the influence of crack depth on the dynamic characteristics of rotor system with a slant crack based on fractional damping is discussed. Here the fractional order is set to $r=0.4$, the rotating speed is set to $\Omega=300 \mathrm{r} / \mathrm{min}$.

The occurrence of a crack will cause the variation in the stiffness of the shaft, the depth of the crack determines the amount of change in the stiffness of the shaft. Therefore, the depth of the crack has a great influence on the dynamic characteristics of the rotor system with a slant crack. From Figure 9 and Figure 10, when the crack depth is shallow, the crack has little effect on the stiffness of the shaft, and the crack information is almost obvious. Moreover, the shaft orbit of rotor system is an ellipse-type shape. In the transverse spectrum diagram, the first harmonic component caused by unbalance is the main component. The second harmonic and other coupling frequency components are relatively weak. In the axial spectrum diagram, the $1 / 2$-order harmonic is the main component, however the first harmonic is relatively weak. The influence of the crack on the stiffness of the shaft becomes more and more obvious with the increase of the crack depth. The shape of the shape orbit gradually changes from an ellipse-type shape to an internal 8-type shape. In the transverse spectrum diagram, the amplitudes of the first harmonic and the other coupling frequency components are almost invariant. However, the amplitude of the second harmonic increases. In the axial spectrum diagram, the amplitude of the second harmonic also increases, however, this increase is relatively slow.

\section{Experimental Study}

The experiment data are collected on the ZT-3 test bench. The vibrational displacement of rotor system in $X$ and $Y$ directions is measured by eddy current sensors. All cracked shafts in the experiment have the same geometric and material properties. The length of the shaft with aslant crack is $L=0.26 \mathrm{~m}$, and the diameter of the shaft is $d=9.5 \mathrm{~mm}$. A crack with a depth of $4 \mathrm{~mm}$ was obtained by wire cut electrical discharge machining (WEDM). The first-order critical speed of the rotor system is $1754.6 \mathrm{r} /$ min.

Figure 11 shows the diagrammatic sketch of bifurcation about the ratio of rotational speed to first-order critical speed. From Figure 11, the bifurcation diagram of the rotor system with a slant crack is separated by three obvious change points, namely, 0.482, 0.577 , and 0.871 . Therefore, the rotational speed $846 \mathrm{r} / \mathrm{min}, 1012 \mathrm{r} / \mathrm{min}$, and $1528 \mathrm{r} / \mathrm{min}$ are selected to evaluate the influence of the speed on dynamic characteristics of rotor system.

Figure 12 shows the shaft orbit and the spectrum of rotor system with a slant crack under the rotating speed

(See figure on next page.)

Figure 6 The transverse and axial spectrum of rotor system with a slant crack based fractional damping (under the different fractional order) 

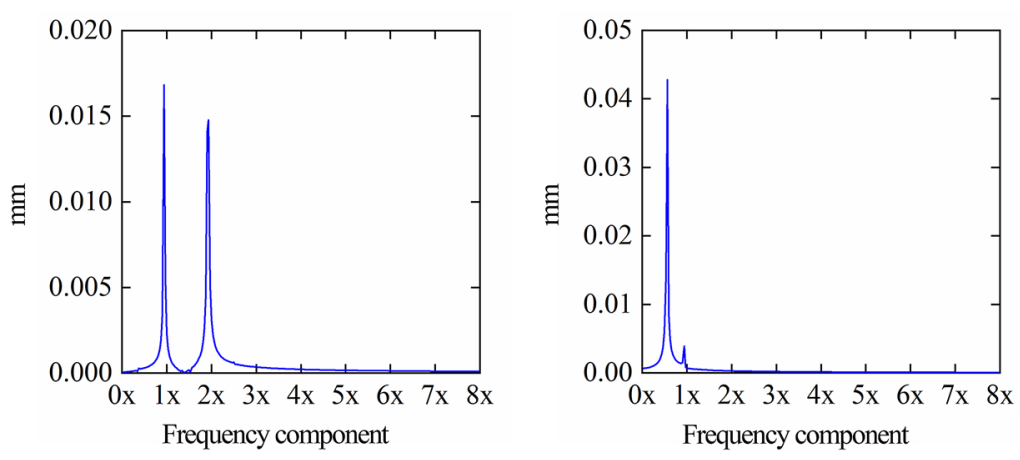

a $r=0.2$
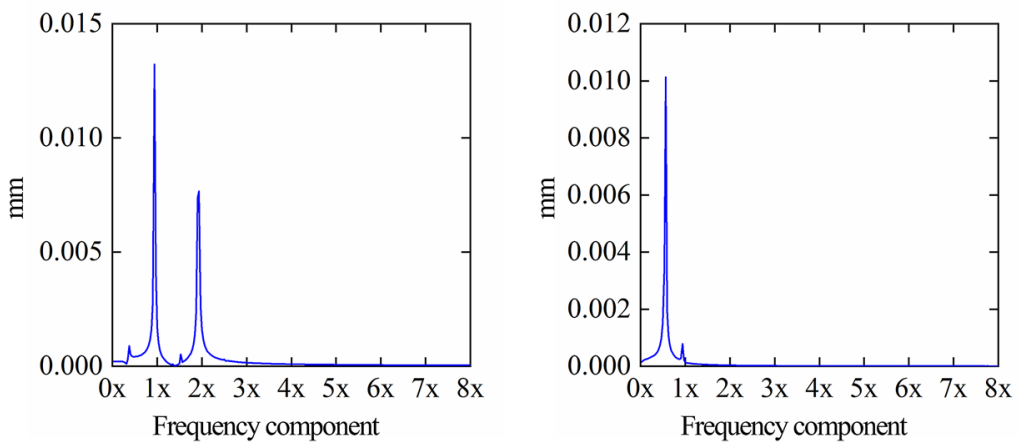

b $r=0.3$

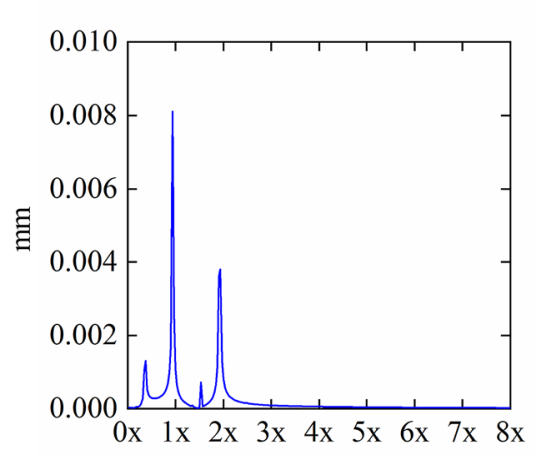

Frequency component

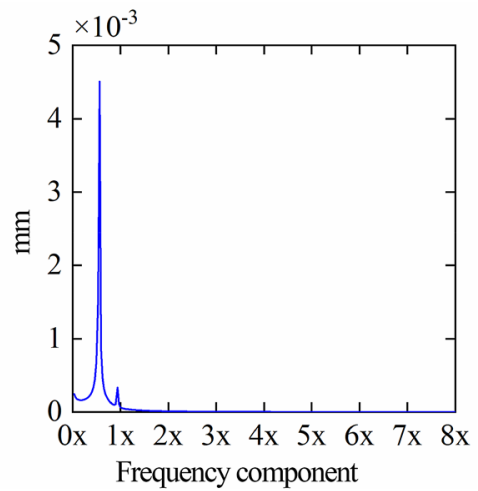

c $r=0.5$
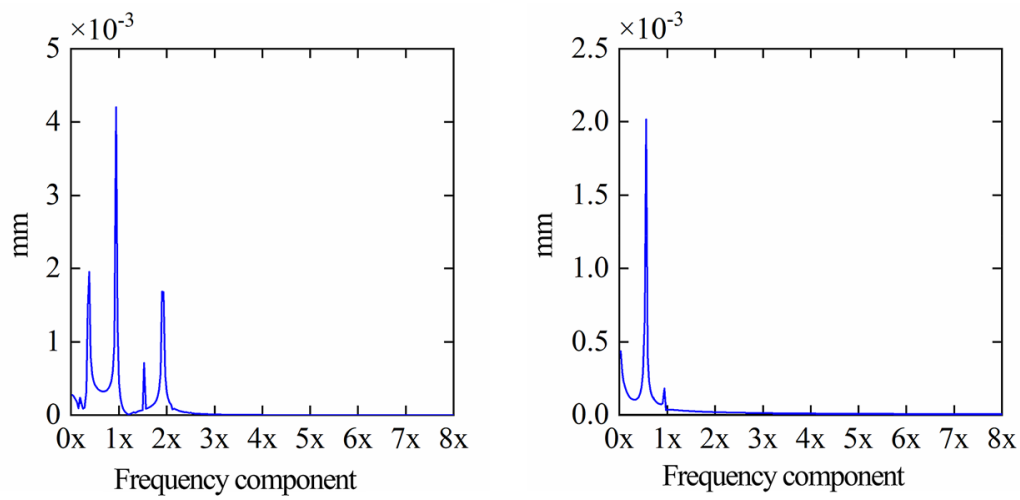

d $r=0.7$ 


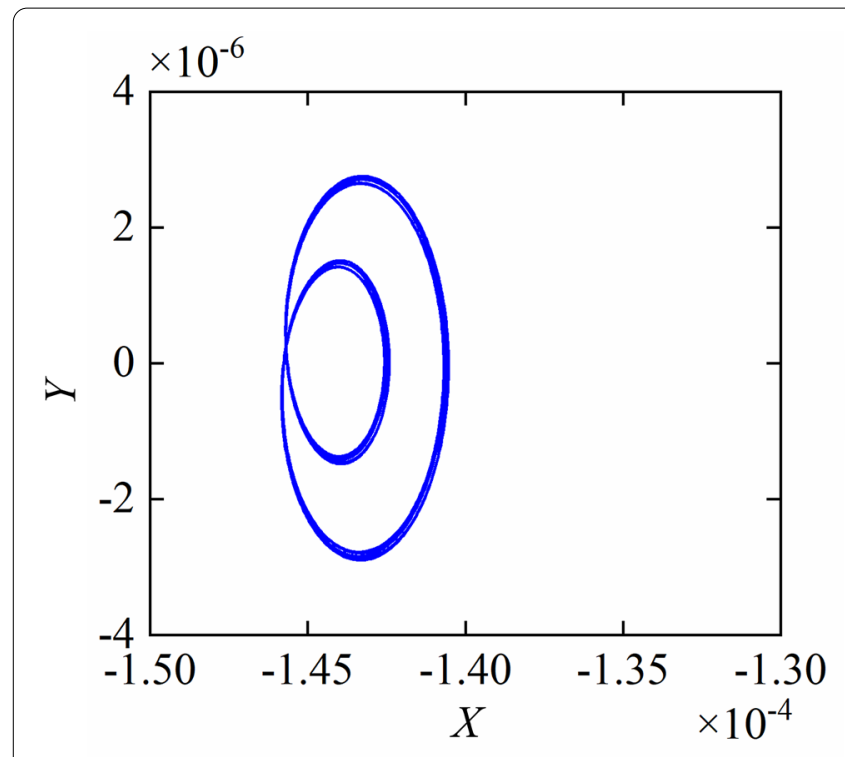

a $\Omega=200 \mathrm{r} / \mathrm{min}$

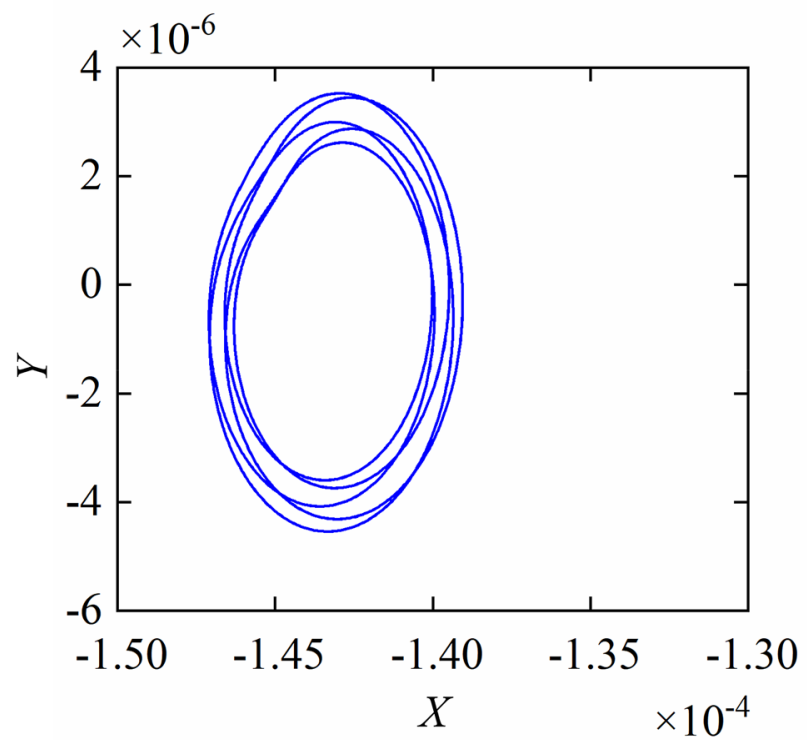

c $\Omega=500 \mathrm{r} / \mathrm{min}$

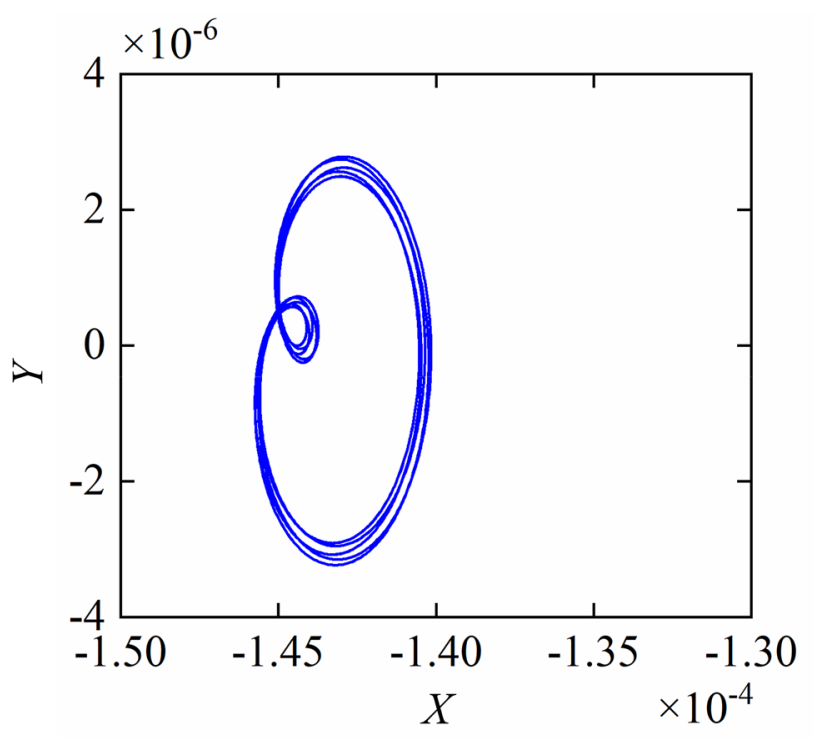

b $\Omega=300 \mathrm{r} / \mathrm{min}$

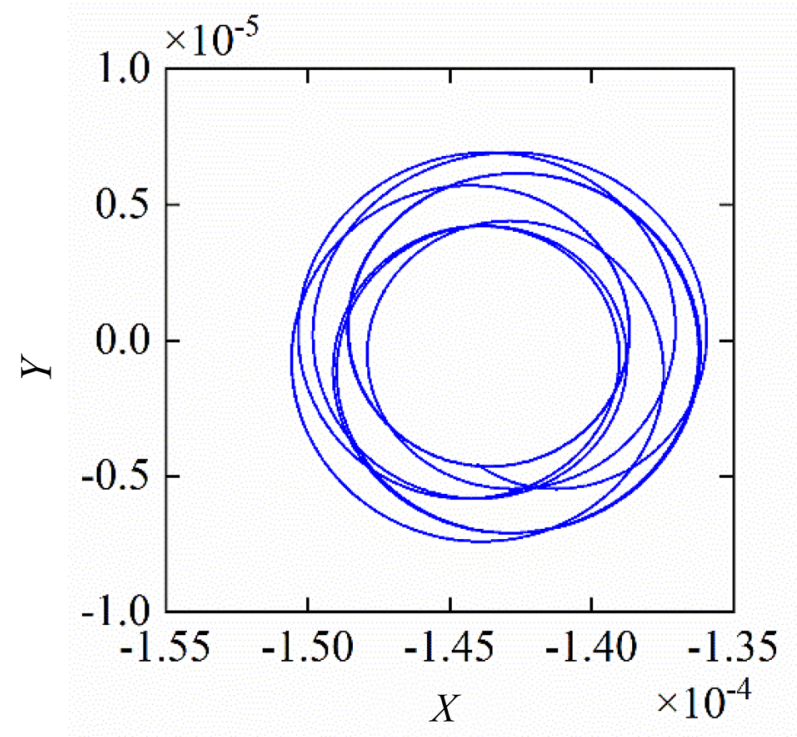

d $\Omega=1000 \mathrm{r} / \mathrm{min}$

Figure 7 Shaft orbit of rotor system with a slant crack based fractional damping (under the different rotating speed) 

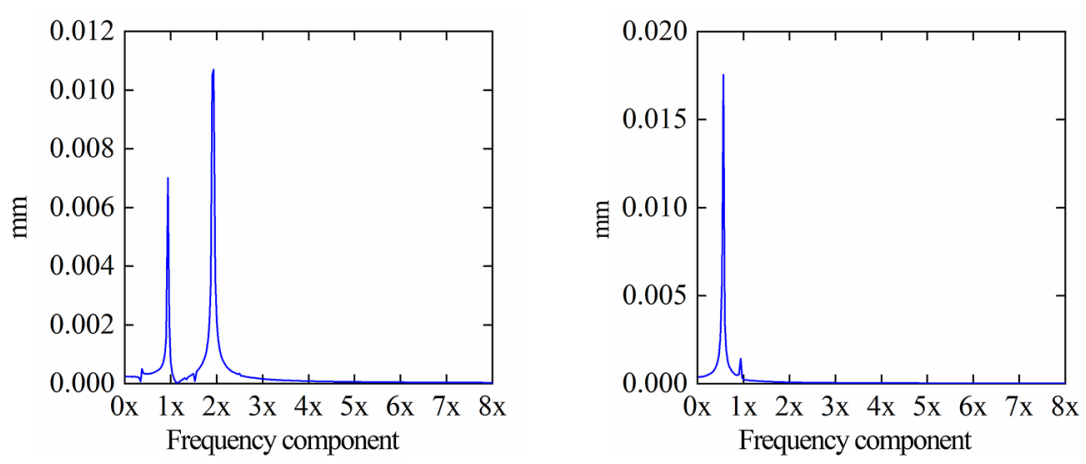

a $\Omega=200 \mathrm{r} / \mathrm{min}$
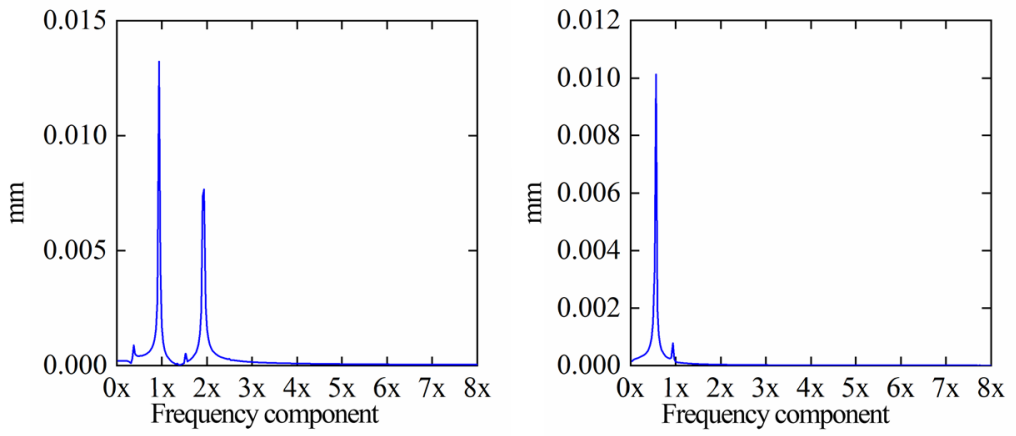

b $\Omega=300 \mathrm{r} / \mathrm{min}$
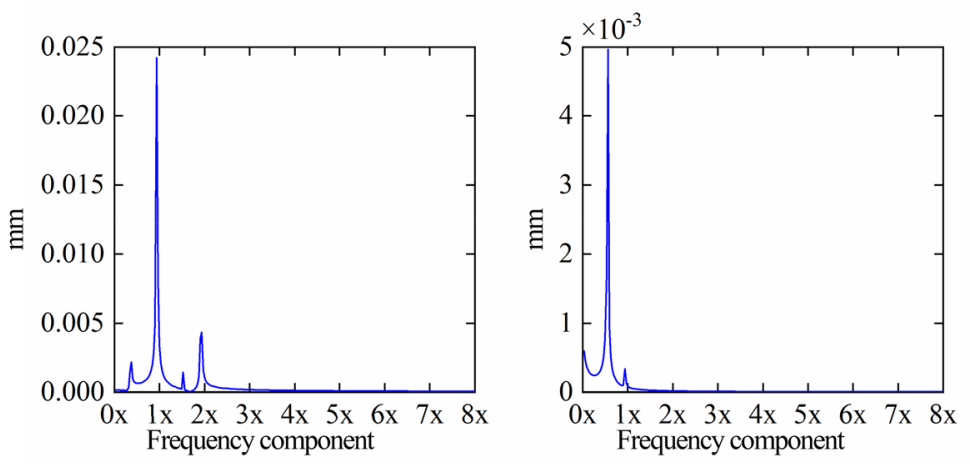

c $\Omega=500 \mathrm{r} / \mathrm{min}$
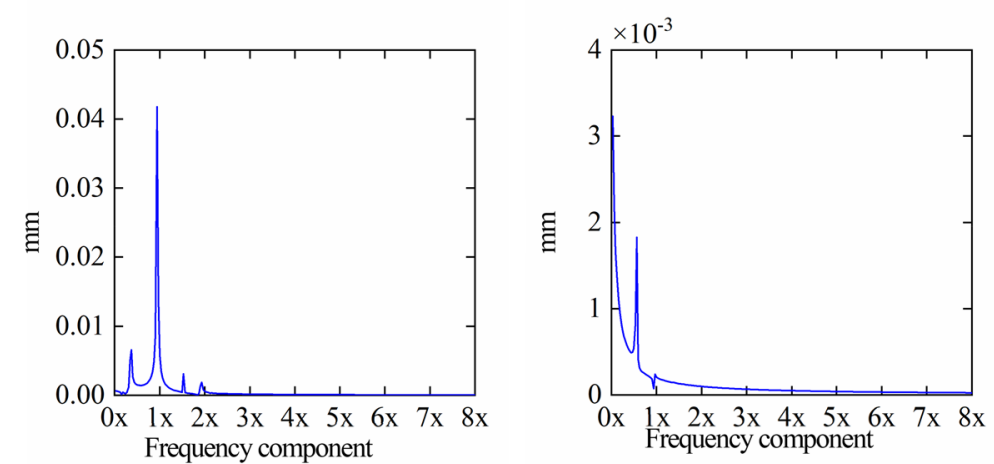

$\mathbf{d}_{\Omega=1000 \mathrm{r} / \mathrm{min}}$ 


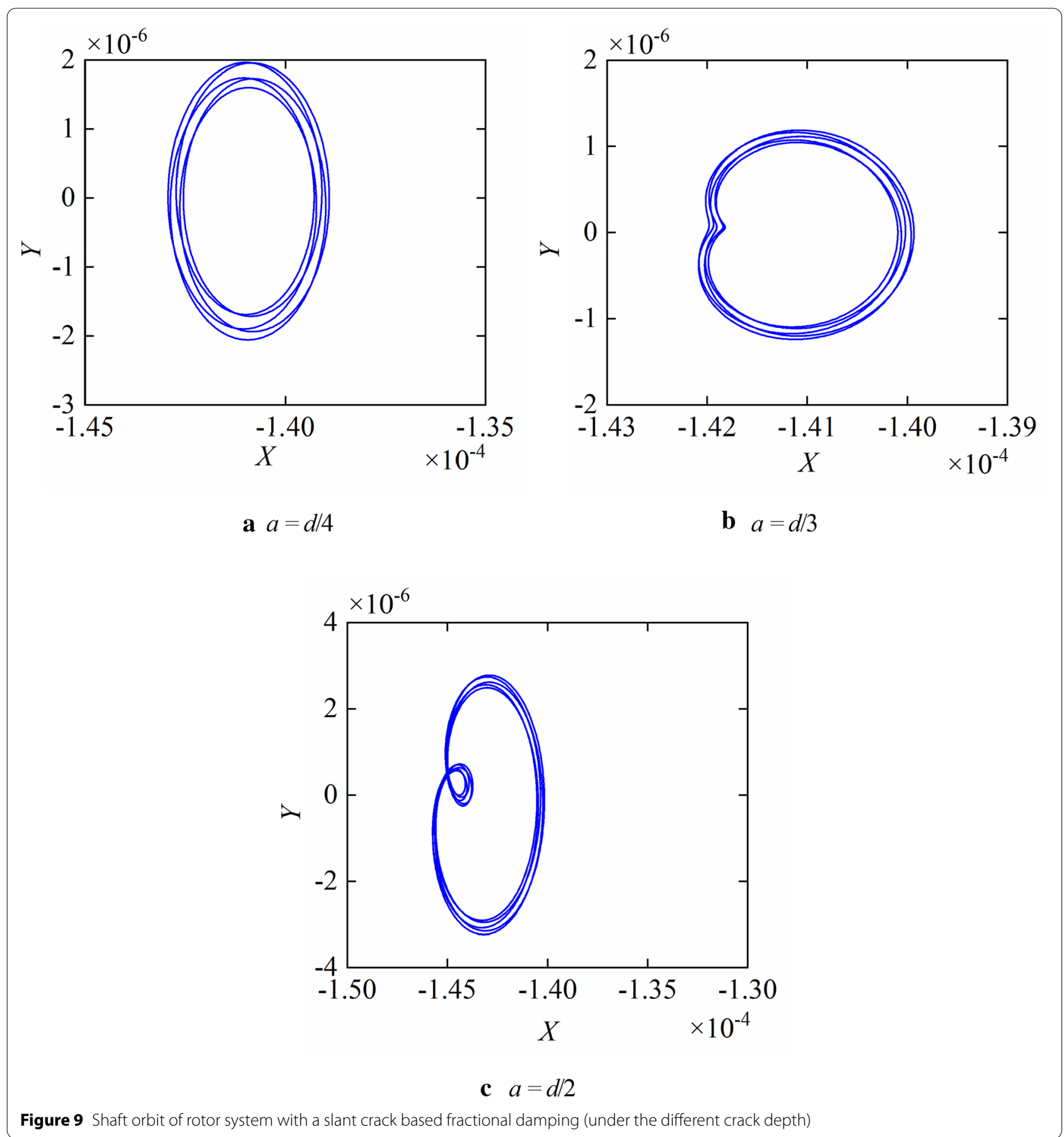



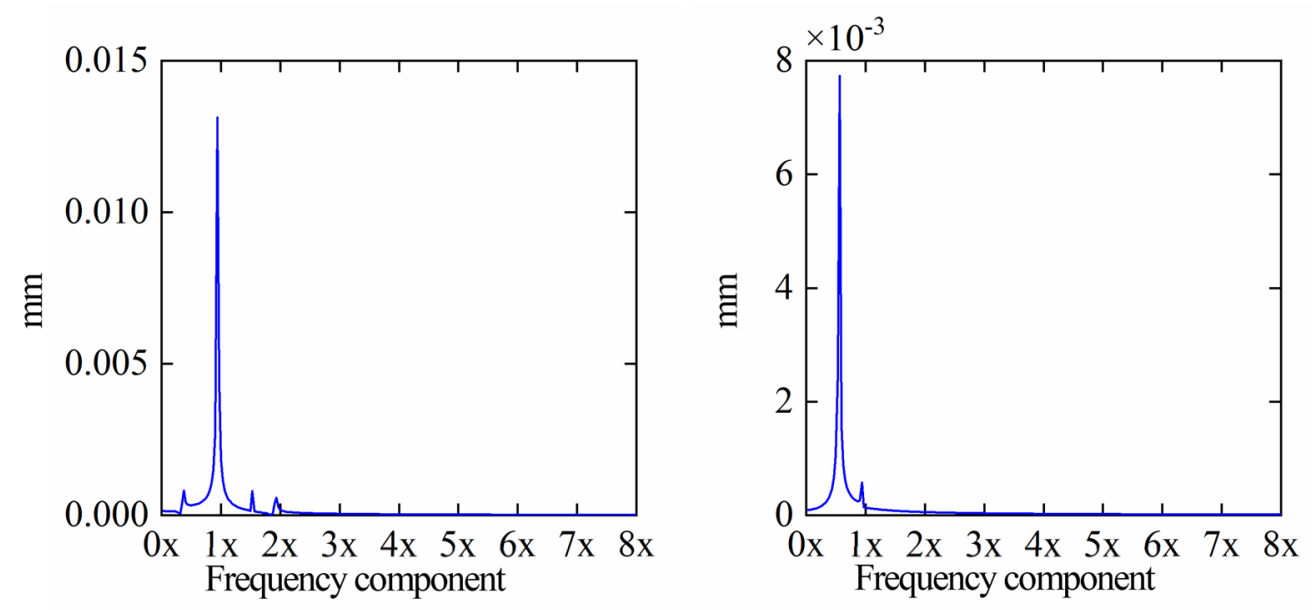

a $a=d / 4$
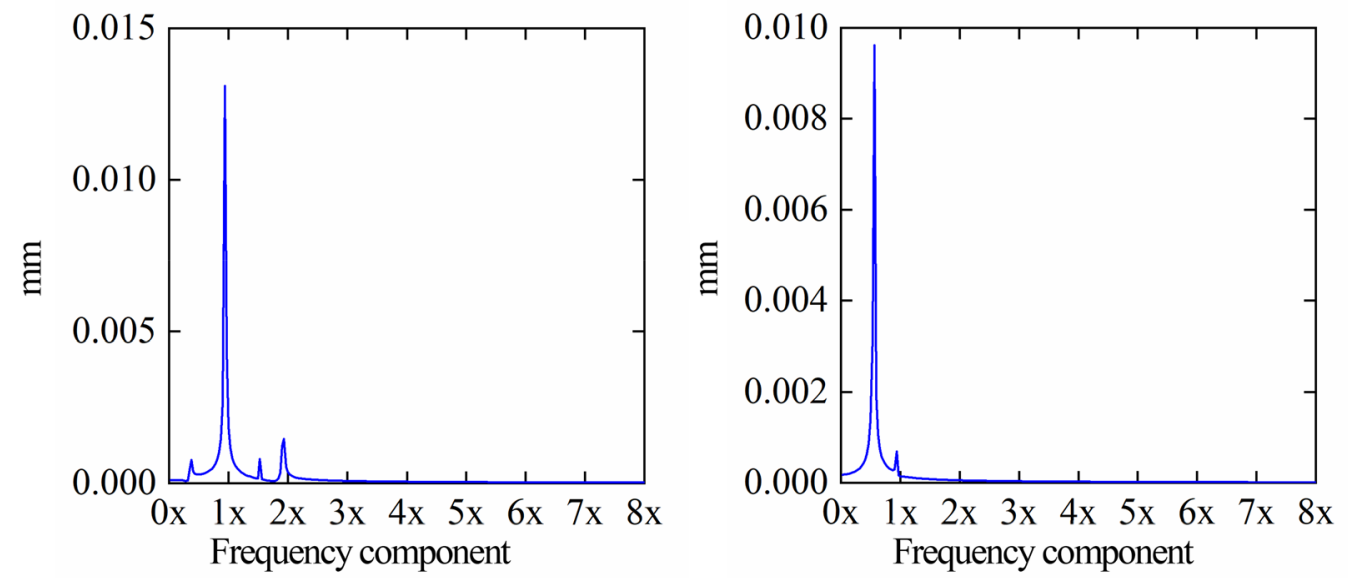

b $a=d / 3$
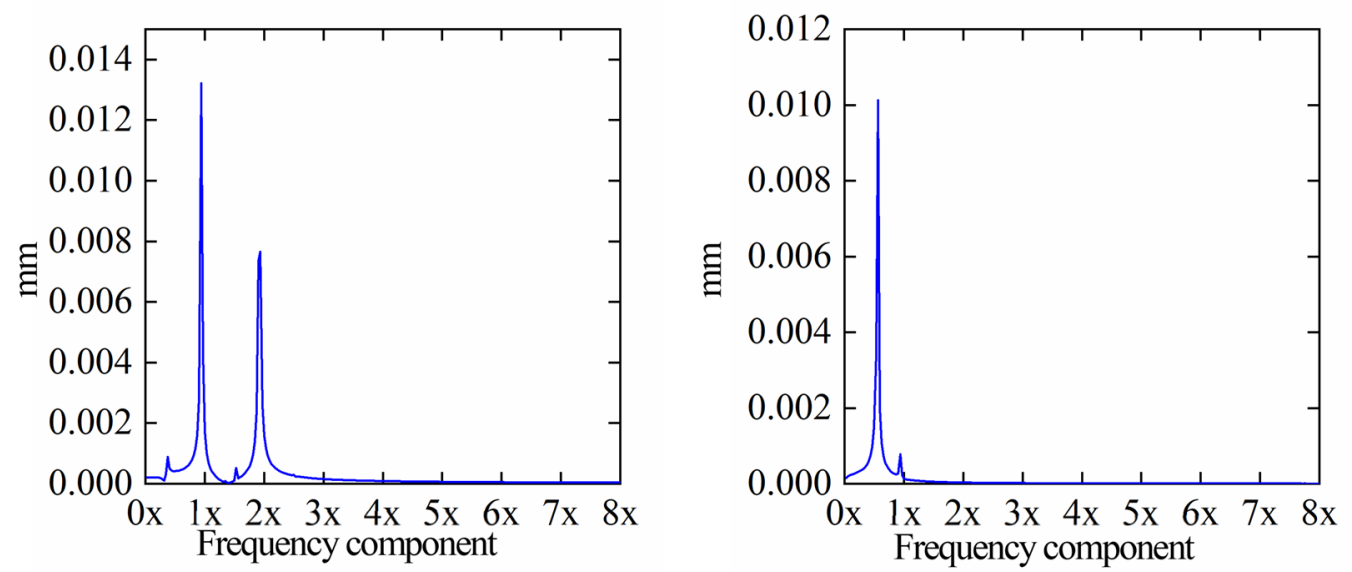

c $a=d / 2$ 


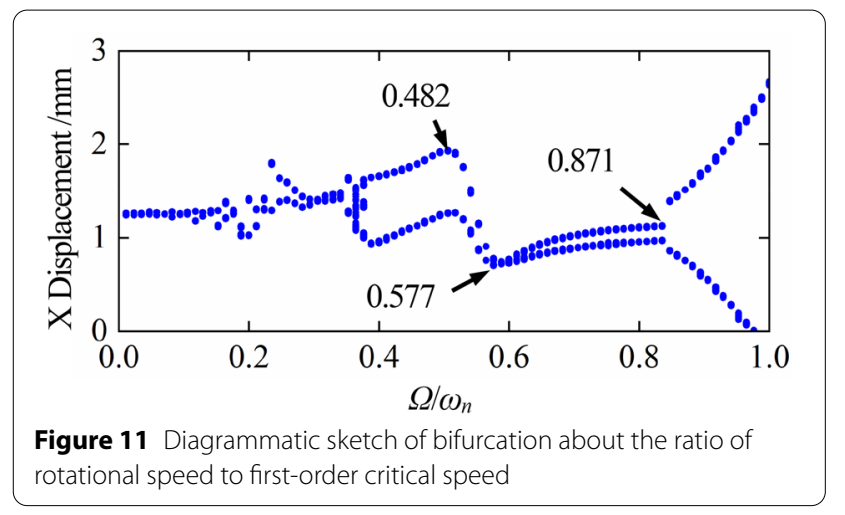

is $846 \mathrm{r} / \mathrm{min}, 1012 \mathrm{r} / \mathrm{min}$, and $1528 \mathrm{r} / \mathrm{min}$, respectively. From Figure 12, the shaft orbit is an internal 8-type shape. Under the rotating speed of $846 \mathrm{r} / \mathrm{min}$, the first harmonic and second harmonic is the main components in the spectrum. In addition, the torsion frequency caused by the excitation of slant crack occurs, and relatively weak coupling frequency components also occur. The shaft orbit gradually changes from an internal 8-type shape to an ellipse-type shape with the increase of the rotating speed. In the spectrum, the amplitude of the second harmonic gradually decreases, the amplitude of the first harmonic increases slowly, and the amplitude of the other frequency components is almost invariant. The experiment results are basically consistent with these of the numerical simulation in the rotor system with a slant crack.

Figure 13 shows the shaft orbit and the spectrum of rotor system under the different depths of the crack. From Figure 13, the experimental results are similar to the simulation results, the shaft orbit changes from an ellipse-type shape to an internal 8-type shape with the increase of the crack depth. At the same time, the amplitude of the second harmonic also increased gradually. 

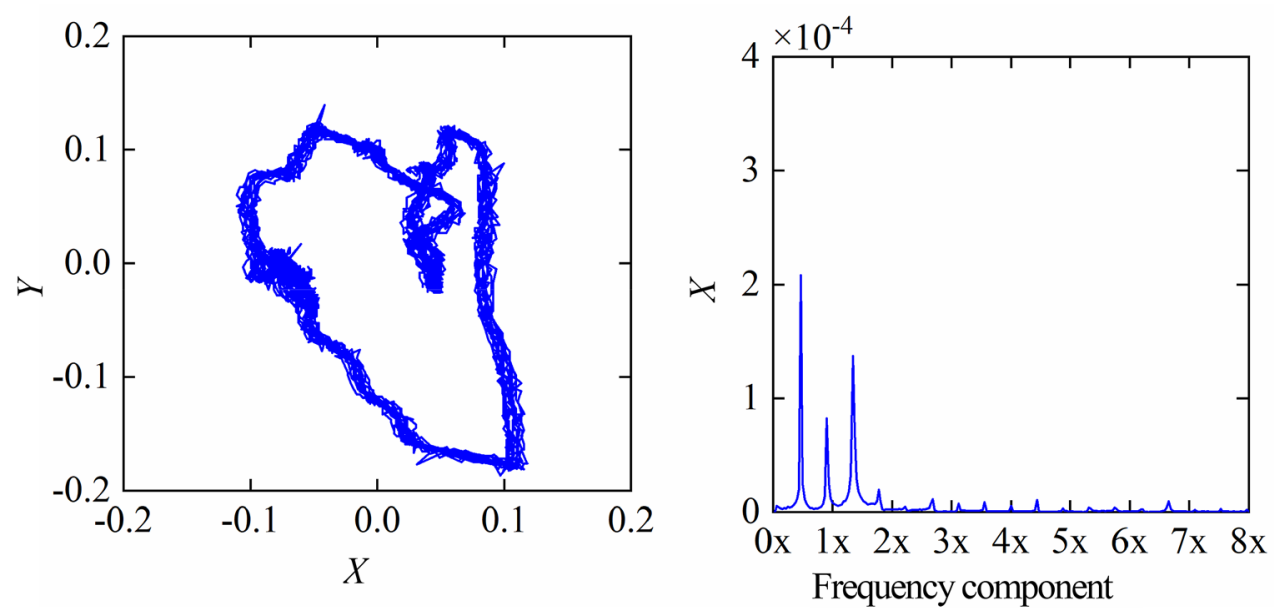

a $\Omega=846 \mathrm{r} / \mathrm{min}$
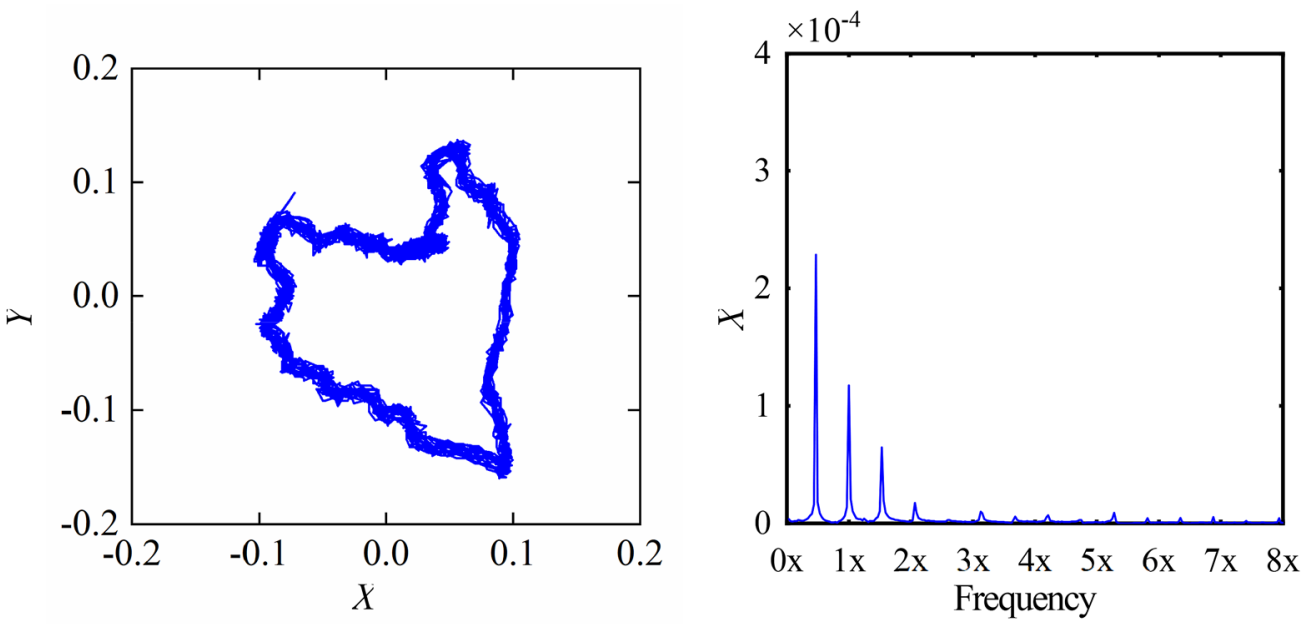

b $\Omega=1012 \mathrm{r} / \mathrm{min}$
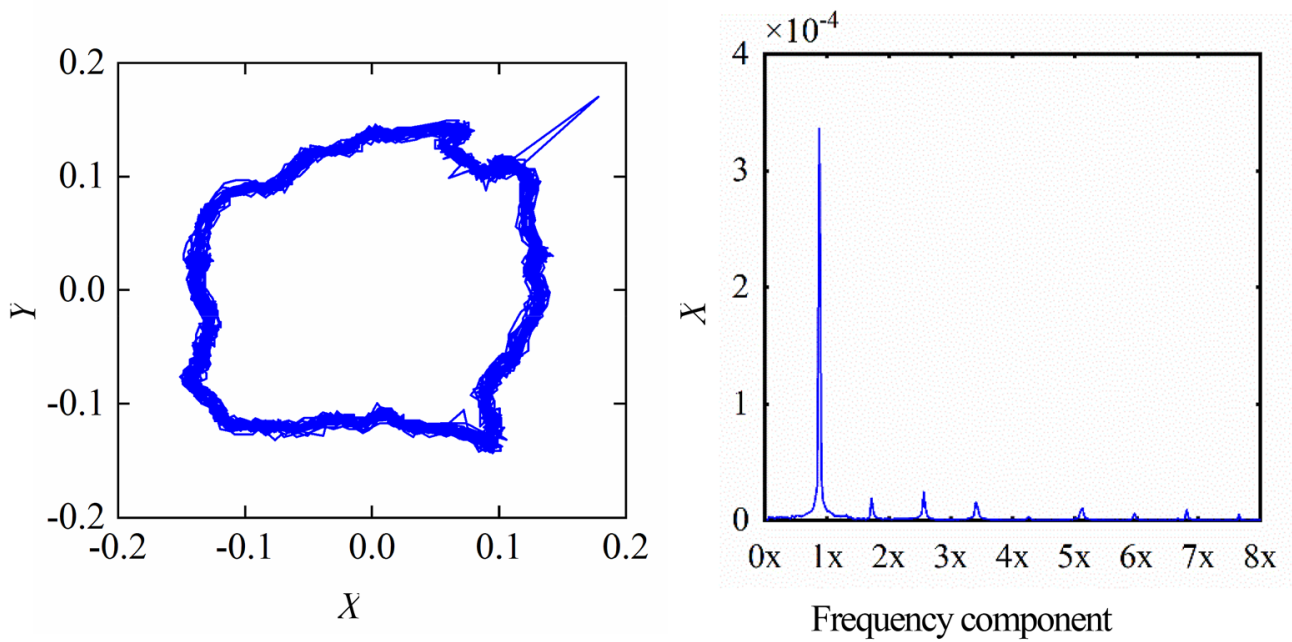

c $\Omega=1528 \mathrm{r} / \mathrm{min}$ 

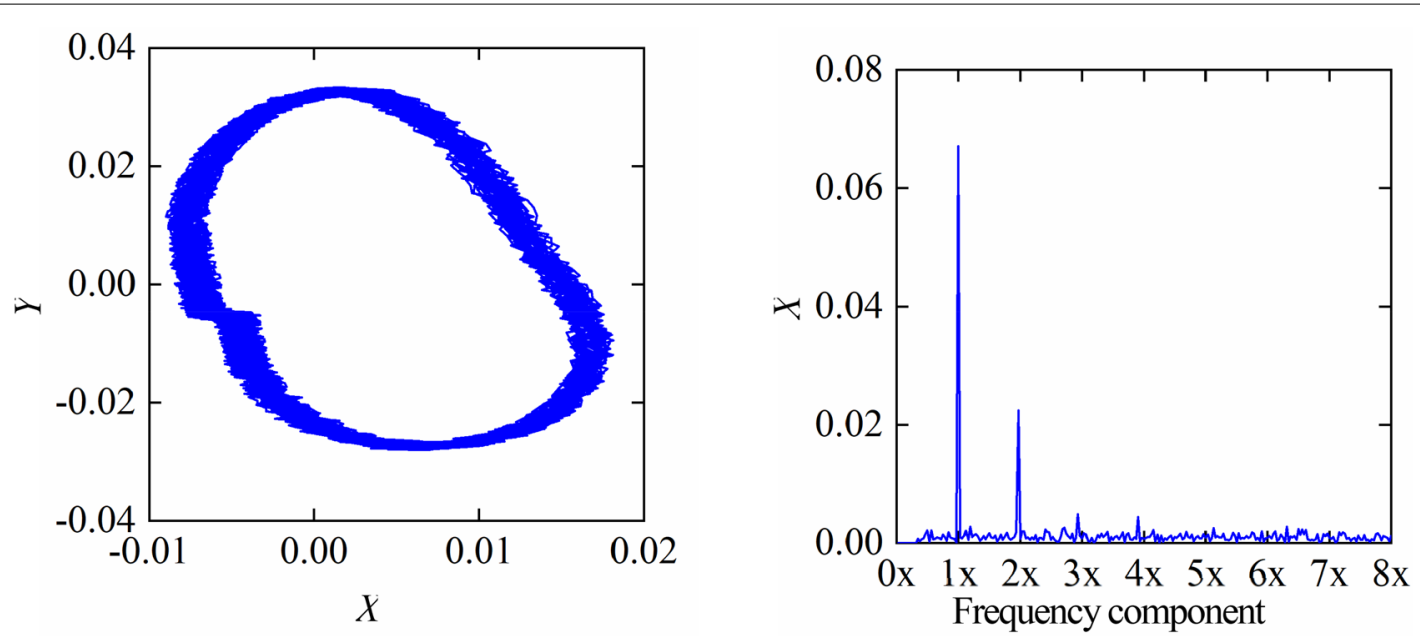

a Shallow crack
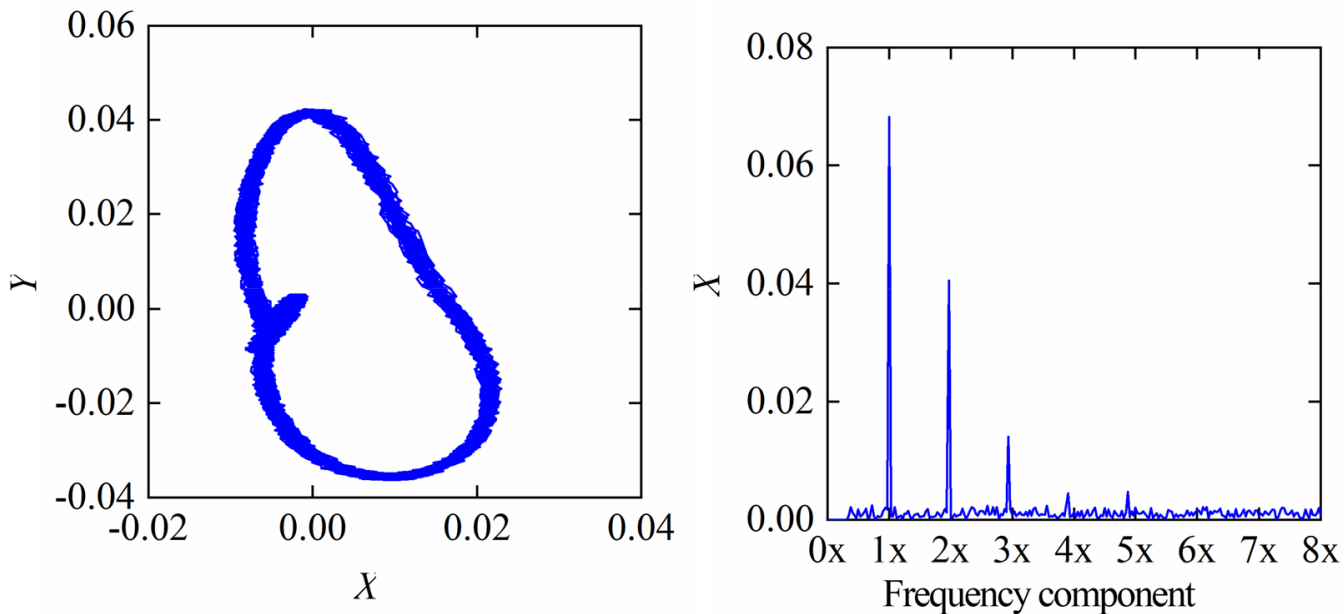

b Medium crack
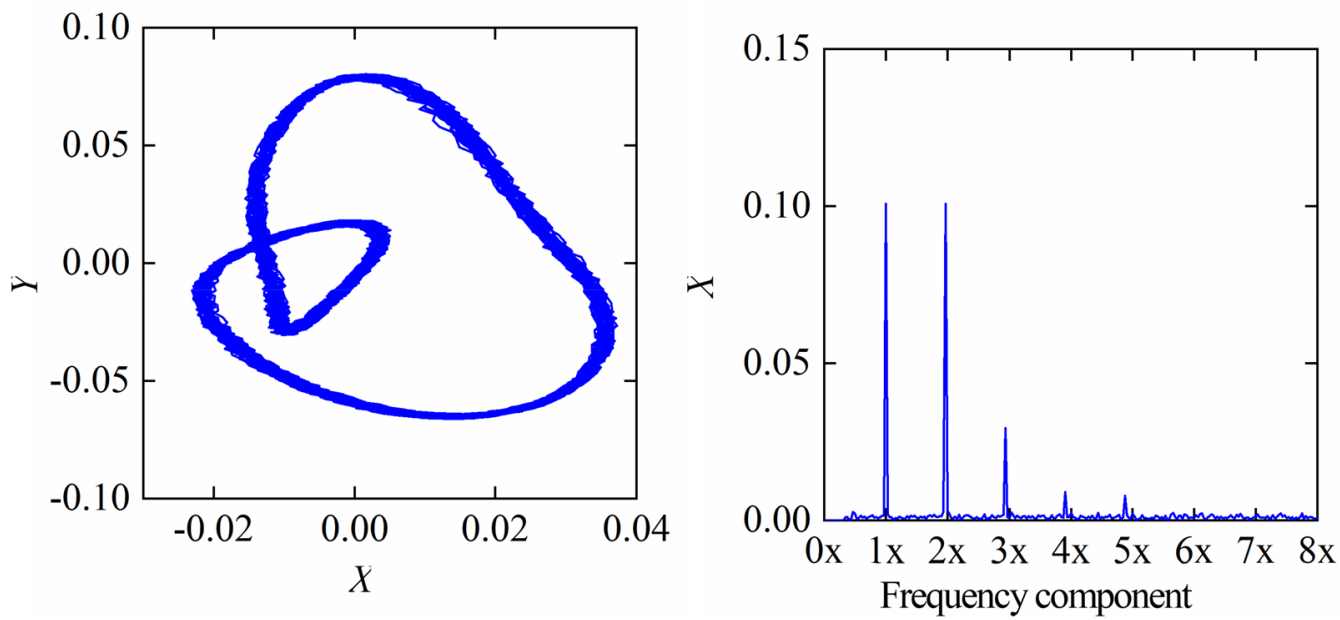

c Deep crack 


\section{Conclusions}

In this paper, the method of $\mathrm{SIF}=0$ is used to solve the stiffness of rotor system with a slant crack. Then, the fractional order calculus is introduced into the modeling of rotor system with a slant crack. The dynamic model of rotor system with a slant crack based on fractional damping is proposed, and the simulation has been successfully completed by numerical methods. The experiment results verified the effectiveness of the proposed model. The influences of fractional order, rotating speed, and crack depth on the nonlinear vibration characteristics of rotor system with a slant crack are discussed. The obtained results are summarized as follows.

1. The variation of fractional order has a great influence on the dynamic characteristics of rotor system with a slant crack. The frequency caused by the torsional excitation and the coupling frequencies increases significantly with the increase of fractional order. Therefore, when the dynamic model of rotor system with a slant crack is established, we can adjust the different fractional order to propose a more realistic rotor system with a slant crack, in order to better study the slant cracks.

2. When the rotating speed close to the critical speed or the subcritical speed, the dynamic characteristics of rotor system with a slant crack are very obvious. We can analyze the dynamic characteristics near the 1/3order or $1 / 2$-order critical speeds, and extract the fault information of rotor system with a slant crack. When the rotor is running at a low speed, the second harmonic is the main component in the spectrum of rotor system with a slant crack. The amplitude of the first harmonic gradually becomes larger as the rotating speed increases. However, the amplitude of the second harmonic and other coupling frequency components is almost invariant. The shaft orbit gradually changes from an internal 8-type shape to an ellipsetype shape without overlapping together.

3. Due to the occurrence of cracks, the stiffness of the shaft changes. The depth of the crack determines the amount of change in the stiffness of the shaft. The vibration amplitude in the transverse direction increases with the increase of the crack depth, and the amplitude of the second harmonic significantly increases. The frequency components caused by the torsional excitation and other coupling frequencies also occur.

\section{Acknowledgements}

Not applicable.

\section{Authors' Contributions}

ZL and DW were in charge of the whole trial, YL wrote the manuscript, and HW assisted with sampling and laboratory analyses. All authors read and approved the final manuscript.

\section{Authors' Information}

Zhinong Li, born in 1966, is currently a professor at Key Laboratory of Nondestructive Testing, Ministry of Education, Nanchang Hangkong University, China. He received his Ph.D. degree from Zhejiang University, China, in 2003. His research interests include mechanical dynamics and fault diagnosis.

Yunlong Li, born in 1993, is currently a master candidate at Key Laboratory of Nondestructive Testing, Ministry of Education, Nanchang Hangkong University, China. His research interests include mechanical dynamics and fault diagnosis.

Dong Wang, born in 1984, is currently an associate professor at State Key Laboratory of Mechanical Systems and Vibration, Shanghai Jiaotong University, China. He received his Ph.D. degree from City University of Hong Kong, China, in 2015. His research interests include mechanical fault diagnosis.

Zhike Peng, born in 1974, is currently a professor at State Key Laboratory of Mechanical Systems and Vibration, Shanghai Jiaotong University, China. He received his Ph.D. degree from Tsinghua University, China, in 2002. His research interests include mechanical dynamics and fault diagnosis.

Haifeng Wang, born in 1987, is currently a master candidate at Key Laboratory of Nondestructive Testing, Ministry of Education, Nanchang Hangkong University, China. His research interests include mechanical dynamics and fault diagnosis.

\section{Funding}

This project is supported by National Natural Science Foundation of China (Grant Nos. 51675258, 51261024, 51265039), State Key Laboratory of Mechanical System and Vibration (Grant No. MSV201914), and Laboratory of Science and Technology on Integrated Logistics Support, National University of Defense Technology (Grant No. 6142003190210).

\section{Competing Interests}

The authors declare no competing financial interests.

\section{Author Details}

${ }^{1}$ Key Laboratory of Nondestructive Testing, Ministry of Education, Nanchang Hangkong University, Nanchang 330063, China. ${ }^{2}$ Laboratory of Science and Technology on Integrated Logistics Support, National University of Defense Technology, Changsha 410073, China. ${ }^{3}$ State Key Laboratory of Mechanical Systems and Vibration, Shanghai Jiaotong University, Shanghai 200240, China.

Received: 3 September 2019 Revised: 24 January 2021 Accepted: 28 January 2021

Published online: 26 February 2021

\section{References}

[1] ZY Lu, L Hou, Y S Chen, et al. Nonlinear response analysis for a dual-rotor system with a breathing transverse crack in the hollow shaft. Nonlinear Dynamics, 2016, 83(1-2): 169-185.

[2] A K Jain, VR, A K Agrawal. Experimental investigation of vibration analysis of multi-crack rotor shaft. Procedia Engineering, 2016, 144: 1451-1458.

[3] C Z Guo, J H Yan, W C Yang. Crack detection for a Jeffcott rotor with a transverse crack: an experimental investigation. Mechanical Systems and Signal Processing, 2017, 83: 260-271.

[4] N G Shul'zhenko, B F Zaitsev, A V Asaenok, et al. Deformation and vibration-induced stress intensity of a high-temperature turbine rotor with a breathing transverse crack. Strength of Materials, 2017, 49(6): 751-759.

[5] C Z Guo, J H Yan, L A Bergman. Experimental dynamic analysis of a breathing cracked rotor. Chin. J. Mech. Eng., 2017, 30: 1177-1183.

[6] H Mobarak, W Helen. Crack breathing behavior of unbalanced rotor system: a quasi-static numerical analysis. Journal of Vibroengineering, 2018, 20(3): 1459-1469. 
[7] C Fu, X M Ren, Y F Yang, et al. Nonlinear response analysis of a rotor system with a transverse breathing crack under interval uncertainties. International Journal of Non-Linear Mechanics, 2018, 105: 77-87.

[8] N A Saeed, M Eissa. Bifurcations of periodic motion of a horizontally supported nonlinear Jeffcott rotor system having transversely cracked shaft. J. Non-Linear Mech., 2018, 101: 113-130.

[9] M Ichimonji, S Watanabe. The dynamics of a rotor system with a shaft having a slant crack. JSME, International Journal, Series III, 1988, 31(4): 712-718.

[10] A S Sekhar, P P Balaji. Dynamic analysis of a rotor system considering a slant crack in the shaft. Journal of Sound and Vibration, 1997, 208(3): 457-473.

[11] A K Darpe. Dynamics of a Jeffcott rotor with slant crack. Journal of Sound and Vibration, 2007, 303(1): 1-28.

[12] A K Darpe. Coupled vibrations of a rotor with slant crack. Journal of Sound and Vibration, 2007, 305(1): 172-193.

[13] Y L Lin, F L Chu, R J Hao. The dynamic characteristics of inclined crack rotor. Journal of Vibration and Shock, 2008, 27(1): 25-29. (in Chinese)

[14] Z N Li, H H Xia, Y X Xiao. Stiffness characteristics analysis of a rotor with slant crack. Journal of Huagiao University (Natural Science), 2016, 37(01): 1-6. (in Chinese)

[15] H H Xia, Z N Li, Y X Xiao. Fault diagnosis method of rotor system with slant crack based on nonlinear output frequency response. Journal of Mechanical Strength, 2017, 39(02): 239-246. (in Chinese)

[16] N Yu. Stiffness characteristics of different crack types of rotors. China Mechanics Conference-2017 and the 60th Anniversary of the Founding of the Chinese Society of Mechanics (B), Beijing, China, August 13-16, 2017: 10. (in (hinese)

[17] W D Jiao, Y H Jiang, J Z Shi, et al. Study on rotor stiffness variation mechanism caused by an arbitrary spatial slant crack. Journal of Vibration Engineering, 2018, 31(3): 490-499. (in Chinese)

[18] ZW Lu, C R Hua, D W Dong, et al. Influence of torsional excitation on dynamic responses of rotors with a breathing slant crack, J. Phys.: Conf. Ser., 2017, 842(1): 012015
[19] J M Balthazar, A M Tusset, V Piccirillo, et al. On nonlinear dynamic of a non-ideal Duffing system with fractional damping. International Conference on Structural Nonlinear Dynamics and Diagnosis, Marrakech, Maroc, May 23-25, 2016, 83: 01002.

[20] D L Yan, W Y Wang, Q J Chen. Fractional-order modeling and dynamic analyses of a bending-torsional coupling generator rotor shaft system with multiple faults. Chaos, Solitons \& Fractals, 2018 110: 1-15.

[21] D L Yan, WY Wang, Q J Chen. Fractional-order modeling and nonlinear dynamic analyses of the rotor-bearing-seal system. Chaos, Solitons \& Fractals, 2020, 133: 109640.

[22] J Y Cao, S M Xue, J Lin, et al. Nonlinear dynamic analysis of a cracked rotor-bearing system with fractional order damping. Journal of Computational and Nonlinear Dynamics, 2013, 8(3): 031008-1-14.

[23] S M Xue, JY Cao, J Lin, et al. Influences of fractional order damping on nonlinear dynamics of cracked rotor. Journal of Xi'an Jiaotong University, 2012, 46(1): 76-80. (in Chinese)

[24] Z Shang. Research on reliability of A7NO1 aluminum alloy welding joints and repair welding. Harbin: Harbin Institute of Technology, 2013. (in Chinese)

[25] Z Liu, J J Wang. Bending stiffness model of a breathing elliptical cracked rotor. Journal of Vibration and Shock, 2016, 35(21): 183-187.

[26] H Tada, P C Paris, G R Irwin. The analysis of cracks handbook. New York: ASME Press, 2000

[27] CX Cao, X D Wang, JWu. Relationship between stress intensity factor and strain energy release rate of I-II-III mixed mode cracks. Journal of Hebei University of Engineering (Natural Science Edition), 2016, 33(04): 10-13+21. (in Chinese)

[28] DY Wang. Research on fault diagnosis of cracked rotor system. Chengdu: Southwest Jiaotong University, 2019. (in Chinese)

[29] N Yu. Model-based rotor crack fault diagnosis method. Nanjing: Nanjing University of Aeronautics and Astronautics, 2018. (in Chinese)

[30] ZW Lu. Research on dynamic characteristics of cracked rotors and crack diagnosis methods. Chengdu: Southwest Jiaotong University, 2017. (in Chinese)

\section{Submit your manuscript to a SpringerOpen ${ }^{\circ}$ journal and benefit from:}

- Convenient online submission

- Rigorous peer review

- Open access: articles freely available online

- High visibility within the field

- Retaining the copyright to your article

Submit your next manuscript at springeropen.com 